\title{
Using Etomidate and Midazolam for Screening Colonoscopies Results in More Stable Hemodynamic Responses in Patients of All Ages
}

\author{
Jung Min Lee ${ }^{1,2}$, Geeho $\mathrm{Min}^{2}$, Bora Keum² , Jae Min Lee ${ }^{2}$, Seung Han Kim², Hyuk Soon Choi $^{2}$, Eun Sun Kim², Yeon Seok \\ $\mathrm{Seo}^{2}$, Yoon Tae Jeen ${ }^{2}$, Hoon Jai Chun ${ }^{2}$, Hong Sik Lee ${ }^{2}$, Soon Ho Um², and Chang Duck Kim² \\ ${ }^{\prime}$ Division of Gastroenterology and Hepatology, Department of Internal Medicine, Wonkwang University Sanbon Medical Center, Gunpo, and \\ ${ }^{2}$ Division of Gastroenterology and Hepatology, Department of Internal Medicine, Institute of Digestive Disease and Nutrition, Korea University \\ Anam Hospital, Seoul, Korea
}

Background/Aims: Recent studies have demonstrated that etomidate is a safe sedative drug with noninferior sedative effects. In our recent study, we revealed that etomidate/midazolam was more hemodynamically stable than propofol/ midazolam in elderly patients undergoing colonoscopies. We aimed to investigate whether compared with propofol/midazolam, etomidate/midazolam causes fewer cardiopulmonary adverse events with noninferior efficacy for screening colonoscopies in patients of all ages. Methods: In this singlecenter, randomized, double-blind study, we prospectively enrolled 200 patients. The patients were divided into etomidate and propofol groups. The primary outcome was the occurrence of cardiopulmonary adverse events. The secondary outcomes were the proportion of patients with fluctuations in vital signs (oxygen desaturation and transient hypotension), adverse events interrupting the procedure, and sedationrelated outcomes. Results: Adverse cardiopulmonary events were more common in the propofol group than the etomidate group (65.0\% vs 51.0\%, respectively; $p=0.045)$. Fortysix patients (46.0\%) in the propofol group and 29 (29.0\%) in the etomidate group experienced fluctuations in their vital signs $(p=0.013)$. The proportions of patients experiencing adverse events that interrupted the procedure, including myoclonus, were not significantly different between the two groups (etomidate: $20.0 \%$ vs propofol: $11.0 \%$; $p=0.079$ ). Both groups had similar sedation-related outcomes. Multivariate analysis revealed that compared with the propofol groups, the etomidate group had a significantly lower risk of fluctuations in vital signs (odds ratio, 0.427; 95\% confidence interval, 0.230 to $0.792 ; p=0.007$ ). Conclusions: Compared with using propofol/midazolam, using etomidate/midazolam for screening colonoscopies results in more stable hemodynamic responses in patients of all ages; therefore, we recommend using etomidate/midazolam for colonoscopies in patients with cardiovascular risk factors. (Gut Liver 2019;13:649-657)

Key Words: Etomidate; Colonoscopy; Propofol; Midazolam; Sedation

\section{INTRODUCTION}

Colonoscopy is the most commonly used method for the diagnosis and treatment of colon disease. ${ }^{1}$ However, colonoscopy is invasive and can be an uncomfortable procedure due to abdominal pain and potential vasovagal reaction. ${ }^{2,3}$ To relieve patients' discomfort, sedative endoscopy is widely used. ${ }^{4}$ In sedative endoscopy, propofol is the most commonly used drug because of its convenience and short action time. ${ }^{2,5}$ However, propofol can have several serious adverse cardiopulmonary effects, such as hypoxia, hypotension, arrhythmia, and respiratory depression. ${ }^{6-8}$

Etomidate is an emerging drug that has improved hemodynamic stability and fewer respiratory depressions compared to propofol. ${ }^{9}$ Similar to propofol, etomidate has short action and recovery time, ${ }^{10}$ but it does not affect the sympathetic tone or myocardial function. ${ }^{11}$ We updated not only for endoscopic retrograde choangiopancreatography and endoscopic ultrasound ${ }^{12,13}$ but for elderly patients with colonoscopy that there were fewer serious cardiopulmonary adverse events in etomi-

\footnotetext{
Correspondence to: Bora Keum

Division of Gastroenterology and Hepatology, Department of Internal Medicine, Institute of Digestive Disease and Nutrition, Korea University Anam Hospital, 73 Inchon-ro, Seongbuk-gu, Seoul 02841, Korea

Tel: +82-2-920-6555, Fax: +82-2-953-1943, E-mail: borakeum@hanmail.net

Received on November 9, 2018. Revised on December 27, 2018. Accepted on January 3, 2019.

pISSN 1976-2283 eISSN 2005-1212 https://doi.org/10.5009/gnl18514

Jung Min Lee and Geeho Min contributed equally to this work as first authors.

(a) This is an Open Access article distributed under the terms of the Creative Commons Attribution Non-Commercial License (http://creativecommons.org/licenses/by-nc/4.0) which permits unrestricted non-commercial use, distribution, and reproduction in any medium, provided the original work is properly cited.
} 
date/midazolam sedation. ${ }^{14}$ However, there were only a few studies about the use of etomidate in all ages with colonoscopy.

In this study, we aimed to investigate whether etomidate/ midazolam has fewer cardiopulmonary adverse events and noninferior efficacy than propofol/midazolam for screening colonoscopy in all ages.

\section{MATERIALS AND METHODS}

\section{Study design}

This single-center, randomized, double-blind study was performed from August 2017 to November 2017 in the Department of Gastroenterology and Digestive Endoscopy at Korea University Anam Hospital (Seoul, Korea). At the time of registration, patients were randomly allocated to either the propofol group or the etomidate group. Patients were randomized using a computer-generated list and were provided with written instructions. All patients provided written informed consent, and this study was approved by the Institutional Review Board of Korea University Hospital (IRB number: ED17153).

\section{Patients}

All patients who were at least 20 years old with an American Society of Anesthesiologists score of I to III and were scheduled to undergo a screening colonoscopy and/or gastroscopy were included in this study. Patients were excluded if they had a known or suspected: (1) desire to undergo colonoscopy without sedation; (2) hypersensitivity to egg products, soybeans, etomidate, or propofol; or (3) adrenocortical insufficiency, chronic corticoid therapy, or porphyria. Patients were also excluded if they: (4) were pregnant or breastfeeding; (5) history of adverse events with prior sedation; or (6) were unable to provide informed consent. If there was hemodynamic instability (systolic blood pressure [SBP] $<90 \mathrm{mmHg}$ ) or if peripheral oxygen saturation (Sp02) was $90 \%$ on room air or $<95 \%$ on 2 $\mathrm{L} / \mathrm{min}$ of oxygen at baseline before the procedure, the patient was withdrawn from the study.

\section{Protocol}

All procedures were performed by a faculty level endoscopist (B.K.). Two well-trained nurses participated in all procedures, both of whom were trained in advanced cardiac life support and completed the propofol sedation training administered by the Korean Society of Gastrointestinal Endoscopy.

All patients were monitored by an endoscopist and two nurses for noninvasive blood pressure, $\mathrm{SpO}_{2}$, electrocardiography, and respiratory activity before and during endoscopy. The patients received $2 \mathrm{~L} / \mathrm{min}$ of nasal oxygen during the procedure, according to the sedation guidelines. ${ }^{15,16}$ One nurse assisted with the procedure, and the other nurse monitored and recorded the patient's vital signs and overall status while the sedative drug was injected. Noninvasive blood pressure was automatically measured every 5 minutes.

In both groups, $0.05 \mathrm{mg} / \mathrm{kg}$ of intravenous midazolam was initially administered. In the etomidate group, a $0.1 \mathrm{mg} / \mathrm{kg}(0.05$ $\mathrm{mL} / \mathrm{kg}$ ) bolus injection of etomidate $(20 \mathrm{mg} / 10 \mathrm{~mL} / \mathrm{A}$; Etomidate Lipuro, B. Braun Korea, Seoul, Korea) was administered. Then, if the Modified Observer's Assessment of Alertness/Sedation (MOAA/S) score was $>3$ points, titration with $0.05 \mathrm{mg} / \mathrm{kg}$ $(0.025 \mathrm{~mL} / \mathrm{kg})$ of etomidate was conducted while the patient's consciousness was assessed. ${ }^{6}$ In the propofol group, a $0.5 \mathrm{mg} /$ $\mathrm{kg}(0.05 \mathrm{~mL} / \mathrm{kg})$ bolus injection of propofol $(120 \mathrm{mg} / 12 \mathrm{~mL}$; Freefol-MCT, Daewon Pharm. Co., Ltd., Seoul, Korea) was administered. Similar to the etomidate group, if the MOAA/S score was $>3$ points after at least 60 seconds of observation, $0.25 \mathrm{mg} /$ $\mathrm{kg}(0.025 \mathrm{~mL} / \mathrm{kg})$ of additional injections were required to maintain appropriate sedation. The MOAA/S score ranges from 0 to 5 ( $0=$ general anesthesia and $5=$ fully awake state), ${ }^{17}$ an adequate target range for the MOAA/S score is $<3$ (patient responds after their name is called loudly or repeatedly) during endoscopy. ${ }^{13,17}$ Because etomidate and propofol are both white and appear identical, the endoscopist and nurses were unaware of which drug was administered in each procedure.

\section{Assessment of patient safety and adverse events}

To reduce discrepancies between endoscopists, one experienced endoscopist performed all endoscopic procedures and used a conventional endoscope (Olympus 290, Tokyo, Japan). In patients undergoing colonoscopy, if they did not have glaucoma or benign prostate hyperplasia, $5 \mathrm{mg}$ of cimetropium bromide (Bropium, 5 mg/mL; Bukwang Pharm Co., Ltd., Seoul, Korea) which caused mild tachycardia and dry mouth, but no serious adverse events were administered at the start of colonoscopy in order to reduce colonic motor response.

One nurse checked the baseline vital signs before the start of the procedure and injected sedatives. When the patient had an MOAA/S score <2, the vital signs were re-checked, and thereafter, the vital signs were recorded every 5 minutes. The endoscopist recorded the induction time and procedure time. Two nurses and one endoscopist recorded all adverse events during the procedure. Duration, onset time, and severity of myoclonus were also recorded. After the procedure, the endoscopists recorded the physician's satisfaction, sedation level during the procedure, and any adverse events. After the patient went to the recovery room, an observer who did not participate in the procedure recorded the patient's satisfaction, recall, nausea or vomiting, and abdominal pain. Patient and endoscopist satisfaction were categorized as low (0-3), medium (4-6), or high (7-10) after recording a numerical rating scale of 0 to $10 .^{13}$

\section{Study endpoint and definitions}

The primary outcome was cardiopulmonary adverse events, including tachycardia, bradycardia, hypertension, transient hypotension, respiratory depression, oxygen desaturation, and 
arrhythmia, during the procedure. ${ }^{18}$ The secondary outcomes were as follows: (1) vital signs fluctuations (VSFs) consisting of oxygen desaturation and transient hypotension; ${ }^{19}$ and (2) adverse events disturbing the procedure, such as belching, severe coughing, need for restraint, and myoclonus. Other secondary outcomes for the efficacy of sedation were induction time, total procedure time, awake time, satisfaction scores of the patients and endoscopists, and any recall.

We defined a major adverse event as endotracheal intubation, permanent neurological disorder, and death. ${ }^{12,13}$ VSFs were defined as transient hypotension (SBP $<90 \mathrm{mmHg}$ or at least 20 $\mathrm{mmHg}$ less than baseline even once during the procedure) and oxygen desaturation $\left(\mathrm{SpO}_{2}<90 \%\right.$ on room air or $<95 \%$ on $2 \mathrm{~L}$ / min of oxygen). Cardiovascular events included tachycardia (heart rate $>110$ beats/min), bradycardia (heart rate $<50$ beats/ min), and arrhythmia (newly developed during the endoscopic procedure). Respiratory depression was defined as the need for any efforts to open the airway through lifting the chin and jaw thrust.

In addition, we defined induction time as the interval from the injection of sedation to the insertion of the endoscope. Total procedure time was defined as the interval from insertion of the endoscope to removal of the endoscope. Awake time was defined the interval between removal of the endoscope and full recovery of the patient (Aldrete score of 10). ${ }^{20}$ Therefore, total sedation time was defined as the interval between administration of sedatives and full recovery of the patient. ${ }^{13}$

\section{Statistical analysis}

In a previous study, ${ }^{21}$ the proportion of patients with adverse cardiopulmonary events was $28 \%$ in a related to propofol administration. When the power was 0.9 and the alpha level was 0.05 , the number of patients per group was 82 . Considering a dropout rate of $10 \%$, the final number of patients was 92 per group. Continuous variables are expressed as mean \pm standard deviation, and discontinuous variables are expressed as counts and percentages. SPSS 24.0 for Windows (IBM Corp., Armonk, NY, USA) was used for data entry and statistical analyses. For the analyses between the treatment groups (etomidate vs propofol), the Student t-test was used to compare continuous variables, as appropriate, and the chi-square test or Fisher exact test was used for categorical data. Binary logistic regression tests were used for multivariate analysis. Any p-values $<0.05$ were considered statistically significant.

\section{RESULTS}

\section{Baseline characteristics}

Initially, 223 patients were assessed. Among them, 23 patients were excluded due to a desire of no sedation $(n=13)$, adrenocortical insufficiency ( $n=3)$, hypersensitivity to the drug $(n=3)$, previous history of adverse events with sedation $(n=2)$, or breastfeeding $(n=2)$ (Fig. 1). Therefore, 200 patients were randomly assigned to two groups: propofol $(n=100)$ and etomidate $(n=100)$. When comparing the two groups, the baseline

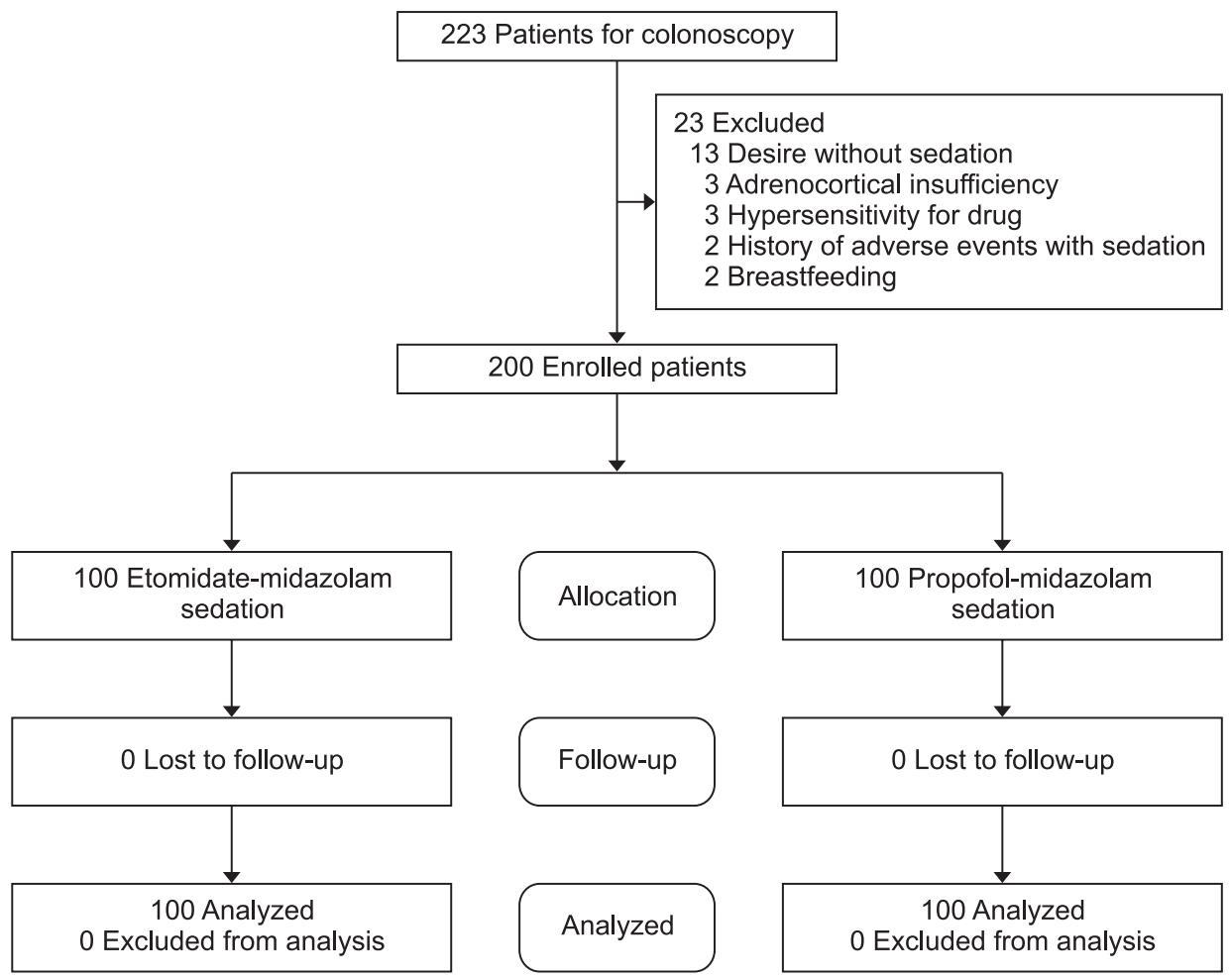

Fig. 1. Recruitment of patients. This flowchart shows the process of recruiting patients for the study. 
Table 1. Baseline Characteristics

\begin{tabular}{|c|c|c|c|c|}
\hline Characteristic & Propofol $(n=100)$ & Etomidate $(\mathrm{n}=100)$ & Total $(n=200)$ & $\mathrm{p}$-value \\
\hline Age, yr & $57.14 \pm 14.50$ & $58.17 \pm 16.28$ & $57.65 \pm 15.38$ & $0.637^{*}$ \\
\hline Male sex & $50(50.0)$ & $54(54.0)$ & $104(52.0)$ & $0.571^{\dagger}$ \\
\hline BMI, $\mathrm{kg} / \mathrm{m}^{2}$ & $23.83 \pm 3.52$ & $23.14 \pm 3.23$ & $23.48 \pm 3.39$ & $0.161^{*}$ \\
\hline Current smoker & $20(20.0)$ & $14(14.0)$ & $34(17.0)$ & $0.259^{\dagger}$ \\
\hline Alcohol abuser & 37 (37.0) & $44(44.0)$ & $81(40.5)$ & $0.313^{\dagger}$ \\
\hline Outpatient & 89 (89.0) & $86(86.0)$ & $175(87.5)$ & $0.521^{\dagger}$ \\
\hline Anticoagulant & $18(18.0)$ & $22(22.0)$ & $40(20.0)$ & $0.436^{\dagger}$ \\
\hline ASA score & & & & $0.557^{\dagger}$ \\
\hline 1 & $43(43.0)$ & $45(45.0)$ & $88(44.0)$ & \\
\hline 2 & $51(51.0)$ & $48(48.0)$ & 99 (49.5) & \\
\hline 3 & $6(6.0)$ & $7(7.0)$ & $13(6.5)$ & \\
\hline Underlying disease & & & & $0.488^{\ddagger}$ \\
\hline None & $43(43.0)$ & $46(46.0)$ & $89(44.5)$ & \\
\hline Hypertension & $29(29.0)$ & $29(29.0)$ & $58(29.0)$ & \\
\hline Diabetes & $8(8.0)$ & $16(16.0)$ & $24(12.0)$ & \\
\hline Chronic liver disease & $1(1.0)$ & $1(1.0)$ & $2(1.0)$ & \\
\hline Coronary artery disease & $2(2.0)$ & $3(3.0)$ & $5(2.5)$ & \\
\hline Chronic kidney disease & $3(3.0)$ & $1(1.0)$ & $4(2.0)$ & \\
\hline Other medical illness & $20(20.0)$ & $13(13.0)$ & $33(16.5)$ & \\
\hline \multicolumn{5}{|l|}{ Baseline vital signs } \\
\hline Baseline SBP, mmHg & $115.50 \pm 21.50$ & $121.17 \pm 19.82$ & $118.85 \pm 20.44$ & $0.663^{*}$ \\
\hline Baseline HR, beats/min & $74.00 \pm 18.07$ & $77.22 \pm 11.90$ & $75.90 \pm 14.61$ & $0.871^{*}$ \\
\hline Baseline $\mathrm{SpO}_{2}, \%$ & $98.69 \pm 1.54$ & $99.04 \pm 1.11$ & $98.90 \pm 1.29$ & $0.434^{*}$ \\
\hline
\end{tabular}

Data are presented as mean \pm SD or number $(\%)$.

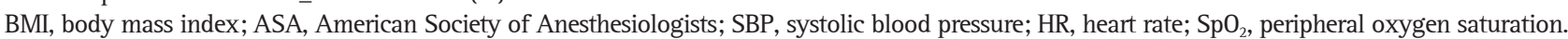
Significant differences between groups were tested by ${ }^{*}$ Student t-test; ${ }^{\dagger}$ chi-square analysis; ${ }^{\ddagger}$ Fisher exact test.

characteristics were not significantly different in terms of age, sex, body mass index, smoking and alcohol history, outpatient status, anticoagulant use, American Society of Anesthesiologists score, underlying diseases, or baseline vital signs (Table 1). In both groups, the administration of midazolam was not significantly different $(\mathrm{p}=0.169)$, and there was no difference in total drug volume between the both group $(\mathrm{p}=0.140)$. Additionally, there were no significant differences in biopsy results $(p=0.258)$, epinephrine injection ( $p=0.323$ ), polypectomy $(p=0.259)$, or cecal intubation time $(\mathrm{p}=0.884)$. Induction time $(\mathrm{p}=0.183)$, procedure time $(p=0.617)$, and awake time $(p=0.178)$ were not significantly different between the groups (Table 2).

\section{Safety-related outcomes}

The occurrence of adverse cardiopulmonary events was significantly higher in the propofol group than the etomidate group (65 vs 51, respectively; $p=0.045$ ). In both groups, there were no major adverse events, including endotracheal intubation, permanent neurologic impairment, or death. Moreover, VSFs were significantly more common in the propofol group than in the etomidate group (46 vs 29 , respectively; $\mathrm{p}=0.013$ ). Adverse events disturbing the procedure were not significantly different between groups (propofol: 11 vs etomidate: $20 ; p=0.079$ ). However, transient hypotension was significantly higher in the propofol group (propofol: 42 vs etomidate: $27 ; \mathrm{p}=0.026$ ). On the other hand, myoclonus was higher in the etomidate group (propofol: 4 vs etomidate: $12 ; \mathrm{p}=0.037$ ) (Table 3 ).

Multivariate logistic regression analysis of the VSFs showed that the odds ratio (OR) of the etomidate group was low (OR, 0.427 ; $95 \%$ confidence interval [CI], 0.230 to $0.792 ; \mathrm{p}=0.007$ ). In addition, a longer procedure time led to more vital sign instability (OR, 2.193; 95\% CI, 1.025 to 4.694; $\mathrm{p}=0.043$ ) (Table 4).

When vital signs change over time (up to 25 minutes of the entire procedure time) were depicted on a scatter plot, median SBP was lower in the propofol group than that in the etomidate group with borderline significance $(p=0.054)$ and SBP of the propofol group significantly decreased while time is passing by $(\mathrm{p}<0.001)$ (Fig. 2A). Median heart rate increased significantly up to 20 minutes of the procedure while time is passing by $(\mathrm{p}<0.001)$ and there was no significant difference between the groups (Fig. 2B). Median $\mathrm{SpO}_{2}$ was sustained above $98 \%$ on $2 \mathrm{~L} / \mathrm{min}$ of oxygen during the procedure; there were no significant group or 
Table 2. Procedure- and Sedation-Related Outcomes

\begin{tabular}{|c|c|c|c|c|}
\hline Outcome & Propofol $(n=100)$ & Etomidate $(\mathrm{n}=100)$ & Total $(n=200)$ & p-value \\
\hline Midazolam, mg & $2.85 \pm 0.66$ & $2.93 \pm 0.56$ & $2.89 \pm 0.61$ & $0.169^{\ddagger}$ \\
\hline Total drug volume, $\mathrm{mL}$ & $13.10 \pm 3.85(131.01 \pm 38.53)^{*}$ & $14.01 \pm 4.75(28.02 \pm 9.50)^{\dagger}$ & $13.56 \pm 4.34$ & $0.140^{\ddagger}$ \\
\hline Cecal intubation time, min & $7.24 \pm 3.07$ & $7.17 \pm 3.35$ & $7.21 \pm 3.21$ & $0.884^{\ddagger}$ \\
\hline \multicolumn{5}{|l|}{ Interventional procedure } \\
\hline Biopsy & $57(57.0)$ & $48(48.0)$ & $105(52.5)$ & $0.258^{\S}$ \\
\hline Epinephrine injection & $35(35.0)$ & $41(41.0)$ & $76(38.4)$ & $0.323^{\S}$ \\
\hline Polypectomy & $41(41.0)$ & $48(48.0)$ & $89(44.9)$ & $0.259^{\S}$ \\
\hline \multicolumn{5}{|l|}{ Sedation time, min } \\
\hline Induction time & $2.30 \pm 1.19$ & $2.51 \pm 1.02$ & $2.41 \pm 1.11$ & $0.183^{\ddagger}$ \\
\hline Procedure time & $27.71 \pm 13.88$ & $28.61 \pm 11.39$ & $28.16 \pm 12.67$ & $0.617^{\ddagger}$ \\
\hline Awake time & $15.25 \pm 10.63$ & $13.18 \pm 11.02$ & $14.12 \pm 10.85$ & $0.178^{\ddagger}$ \\
\hline Patients & & & & $0.335^{\prime \prime}$ \\
\hline Dissatisfied (0-3) & $1(1.0)$ & 0 & $1(0.5)$ & \\
\hline Ordinary (4-6) & $11(11.0)$ & $7(7.0)$ & $18(9.0)$ & \\
\hline Satisfied (7-10) & $88(88.0)$ & $93(93.0)$ & $181(90.5)$ & \\
\hline Endoscopists & & & & $0.188^{\S}$ \\
\hline Dissatisfied (0-3) & 0 & 0 & 0 & \\
\hline Ordinary (4-6) & $29(29.0)$ & $20(20.0)$ & $49(24.5)$ & \\
\hline Satisfied (7-10) & $71(71.0)$ & $80(80.0)$ & $151(75.5)$ & \\
\hline Pain after procedure & & & & $1.000^{\prime \prime}$ \\
\hline None & $94(94.0)$ & $95(95)$ & $189(94.5)$ & \\
\hline Mild & $5(5.0)$ & $5(5.0)$ & $10(5.0)$ & \\
\hline Severe & $1(1.0)$ & 0 & $1(0.5)$ & \\
\hline Nausea or vomiting after procedure & & & & $0.622^{\prime \prime}$ \\
\hline None & $86(86.0)$ & $90(90.0)$ & $176(88.0)$ & \\
\hline Mild & $12(12.0)$ & $9(9.0)$ & $21(10.5)$ & \\
\hline Severe & $2(2.0)$ & $1(1.0)$ & $3(1.5)$ & \\
\hline Any recall & & & & $0.080^{\prime \prime}$ \\
\hline None & $95(95.0)$ & $86(86.0)$ & $181(90.5)$ & \\
\hline Uncertain & $5(5.0)$ & $3(3.0)$ & $8(4.0)$ & \\
\hline Recall & $5(5.0)$ & $14(14.0)$ & $19(9.5)$ & \\
\hline
\end{tabular}

Data are presented as mean \pm SD or number $(\%)$.

${ }^{*}$ Propofol, $10 \mathrm{mg}$ per $1 \mathrm{~mL}$; ${ }^{\dagger}$ Etomidate, $2 \mathrm{mg}$ per $1 \mathrm{~mL}$. Significant differences between groups were tested by ${ }^{\ddagger}$ Student t-test; ${ }^{\S}$ chi-square analysis; "Fisher exact test.

time differences (Fig. 2C).

\section{Efficacy related outcomes}

The quality of sedation during endoscopy was assessed by an observer using a questionnaire. The efficacy of sedation, including patient and endoscopist satisfaction; abdominal pain after the procedure; and nausea or vomiting after the procedure, are shown in Table 2. There was no significant difference between the groups in terms of patient satisfaction $(p=0.335)$ and endoscopist satisfaction ( $\mathrm{p}=0.188$ ). In addition, differences between the groups for abdominal pain $(p=1.000)$ and nausea or vomiting $(\mathrm{p}=0.622)$ after the procedure were not statistically significant. Further, the frequency of recall was not significantly different between the etomidate and propofol groups ( $\mathrm{p}=0.080$ ).

\section{DISCUSSION}

Before this study, we compared etomidate/midazolam with propofol/midazolam in elderly patients with colonoscopy. ${ }^{14}$ As a further study of previous one, we performed this study on a larger number of patients of all ages. In the present study, we demonstrated the sedative efficacy and safety of etomidate and propofol for midazolam-based colonoscopy in all ages. In addition, we revealed that the etomidate/midazolam group had a 
Table 3. Major and Minor Adverse Events

\begin{tabular}{|c|c|c|c|c|}
\hline Adverse events & Propofol $(n=100)$ & Etomidate $(n=100)$ & Total $(n=200)$ & p-value* \\
\hline Major adverse events & 0 & 0 & 0 & 1.000 \\
\hline \multicolumn{5}{|l|}{ Minor adverse events } \\
\hline None & $38(38.0)$ & $34(34.0)$ & $72(36.0)$ & 0.556 \\
\hline All cardiopulmonary adverse events & $65(65.0)$ & $51(51.0)$ & $116(58.0)$ & 0.045 \\
\hline Oxygen desaturation & $4(4.0)$ & $2(2.0)$ & $6(3.0)$ & 0.279 \\
\hline Respiratory depression & $5(5.0)$ & $3(3.0)$ & $8(4.0)$ & 0.470 \\
\hline Transient hypotension & $42(42.0)$ & $27(27.0)$ & $69(34.5)$ & 0.026 \\
\hline Transient hypertension & $6(6.0)$ & $3(3.0)$ & $9(4.5)$ & 0.498 \\
\hline Arrhythmia during procedure & 0 & 0 & 0 & 1.000 \\
\hline Bradycardia & $1(1.0)$ & $3(3.0)$ & $4(2.0)$ & 0.302 \\
\hline Tachycardia & $7(7.0)$ & $13(13.0)$ & $20(10.0)$ & 0.157 \\
\hline Vital sign fluctuation & $46(46.0)$ & $29(29.0)$ & $75(37.5)$ & 0.013 \\
\hline Adverse events disturbing procedure & $11(11.0)$ & $20(20.0)$ & $31(15.5)$ & 0.079 \\
\hline Severe coughing & $2(2.0)$ & $2(2.0)$ & $4(2.0)$ & 1.000 \\
\hline Belching & $1(1.0)$ & $2(2.0)$ & $3(1.5)$ & 0.155 \\
\hline Needs for restraint & $4(4.0)$ & $4(4.0)$ & $8(4.0)$ & 1.000 \\
\hline Myoclonus & $4(4.0)$ & $12(12.0)$ & $16(8.0)$ & 0.037 \\
\hline
\end{tabular}

Data are presented as number (\%).

*Significant differences between groups were tested by chi-square analysis.

Table 4. Multivariate Analysis of Fluctuations in Vital Signs

\begin{tabular}{lcc}
\hline & OR $(95 \% \mathrm{CI})$ & p-value \\
\hline Etomidate group & $0.427(0.230-0.792)$ & 0.007 \\
Female sex & $1.127(0.599-2.121)$ & 0.710 \\
Age, yr & $1.000(0.977-1.023)$ & 0.977 \\
BMI, kg/m & $0.927(0.841-1.022)$ & 0.128 \\
Procedure time & $2.193(1.025-4.694)$ & 0.043 \\
\multicolumn{1}{c}{ More than 20 min } & $0.696(0.303-1.598)$ & 0.392 \\
Hypertension & 1 & \\
ASA score & $1.854(0.816-4.215)$ & 0.140 \\
1 & $1.638(0.438-6.128)$ & 0.463 \\
2 & & \\
\hline
\end{tabular}

OR, odds ratio; CI, confidence interval; BMI, body mass index; ASA, American Society of Anesthesiologists.

*Binary logistic regression tests were used for multivariate analysis.

lower risk of hemodynamic instability on multivariate analysis, even after removing the effects of other variables. We included patients' information regarding underlying diseases, and American Society of Anesthesiologists scores II and III classes, as well as identified healthy patients. Last, we confirmed an association between procedure time and VSF that was not identified in previous our studies.

Although etomidate is similar to propofol in terms of rapid action and recovery, etomidate results in more hemodynamic stability, especially transient hypotension and it can be used for patients with shock or severe cardiovascular disease. ${ }^{22,23} \mathrm{Al}-$ though a single dose does not have long-term effects, ${ }^{24}$ a known disadvantage of etomidate is adrenal insufficiency by inhibiting the synthesis of glucocorticoids and mineral corticoids through blocking of 11- $\beta$-hydroxylation in the adrenal gland. ${ }^{25}$ Other common side effects are myoclonus and post-procedural nausea and vomiting. Recent studies have shown that adverse cardiopulmonary events occur less often in patients receiving etomidate during advanced endoscopic procedures. ${ }^{9,12,13}$ Based on these studies, we assumed that etomidate had hemodynamic stability and a non-inferior efficacy of sedation for diagnostic endoscopy, as well as for advanced endoscopic procedures.

Midazolam is a benzodiazepine drug that acts on the $\gamma$-aminobutyric acid (GABA) receptor and has strong amnestic, anxiolytic, and sedative effects. ${ }^{26}$ However, midazolam has disadvantages because it takes a long time to induce sedation and has a delayed recovery time because of its relatively long half-life. ${ }^{27,28}$ Balanced sedation with low-dose midazolam and propofol is a commonly used regimen that is effective and safe. ${ }^{11}$ Although there is a previous study of etomidate/remifentanil for colonoscopy in a small population, ${ }^{29}$ to the best of our knowledge, there are no studies that investigated etomidate/midazolam compared to propofol/midazolam for colonoscopy in all ages. For these reasons, we designed a comparison study showing that etomidate/midazolam can be used safely and effectively, even during screening colonoscopy in all ages.

We assumed that there would be a smaller proportion of patients with transient hypotension and oxygen desaturation in 
A

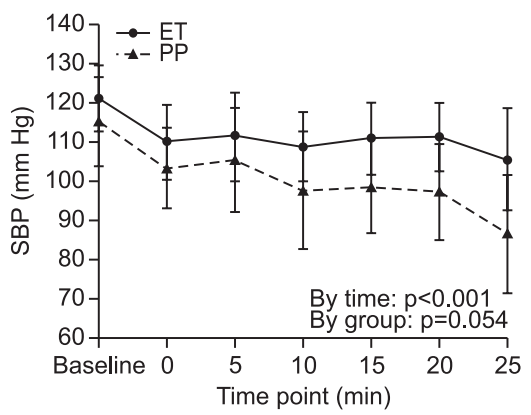

B

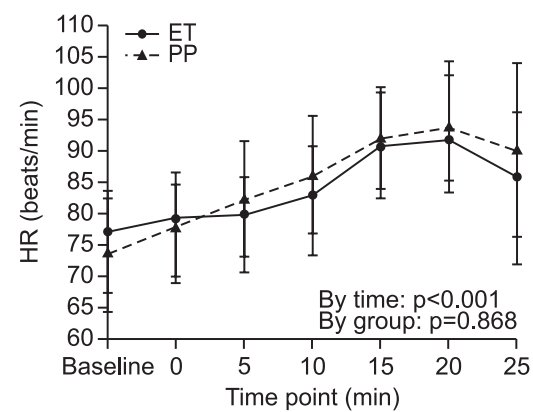

C

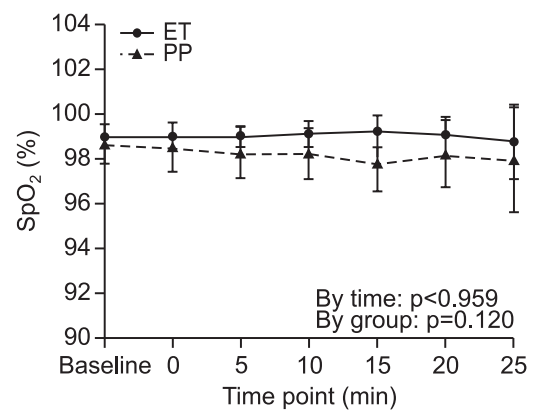

Fig. 2. Changes in vital signs over time. (A) Time course of changes in SBP (mmHg). (B) Time course of changes in HR (per minutes). (C) Time course of changes in $\mathrm{SpO}_{2}(\%)$.

$\mathrm{SBP}$, systolic blood pressure; ET, etomidate group; PP, propofol group; HR, heart rate; $\mathrm{SpO}_{2}$, peripheral oxygen saturation.

the etomidate group. VSF and adverse cardiopulmonary events, especially transient hypotension were significantly higher in the propofol group. In addition, patients in the propofol group experienced more fluctuations when vital signs changes were observed over time. Myoclonus occurred in 12\% of patients in the etomidate group; this is consistent with a study that showed that midazolam premedication reduced myoclonus compared to that reported by a previous etomidate/remifentanil study. ${ }^{30,31}$ In addition, for this double-blinded study, we initially used $0.1 \mathrm{mg} / \mathrm{kg}$ of etomidate, which was slightly less than the usual single dose of etomidate $(0.15-0.20 \mathrm{mg} / \mathrm{kg}){ }^{32}$ However, while both midazolam and etomidate act on GABA receptors, they have a synergistic effect that adjusts the dose through balanced sedation. Although midazolam has no analgesic effect and a longer half-life, this study had no specific adverse events related to midazolam following the procedure compared to a previous remifentanil/etomidate study. ${ }^{29}$

Similar to a previous study, ${ }^{11,12,14}$ we demonstrated that in all ages, an etomidate/midazolam combination resulted in fewer transient hypotension and there was no difference in sedationrelated outcomes. Therefore, propofol sedation should be performed according to the guidelines in low-risk patients, and etomidate/midazolam can be used selectively in patients with a high cardiovascular risk considering the degree of systemic disease, the degree of functional limitation, life-threatening status, and high BMI. Furthermore, the longer the procedure, the higher vital sign instability was provoked; therefore, etomidate has an advantage in longer procedures than propofol.

There are limitations to our study. First, we did not investigate oversedation or undersedation. It would be better if we could measure the degree of sedation according to the time. Second, although a single dose affects steroidogenesis only up to 72 hours, we did not measure cortisol and adrenocorticotropic hormone levels. Third, we did not assess factors related to the airway, such as the Mallampati class. ${ }^{16}$ Fourth, patients with both gastroscopy and colonoscopy may lead bias. However, the rate of patients who receive both gastroscopy and colonoscopy was not significantly different between etomidate-midazolam and propofol-midazolam.

In conclusion, etomidate/midazolam administration for sedation during colonoscopy is safe and result in stable hemodynamic responses in young patients as well as elderly patients. Although etomidate/midazolam administration is more frequently associated with myoclonus, we recommend an etomidate/midazolam regimen as a promising sedation method for colonoscopy in patients with vulnerable risk factors.

\section{CONFLICTS OF INTEREST}

No potential conflict of interest relevant to this article was reported.

\section{ACKNOWLEDGEMENTS}

This research was supported by a grant of the Korea Health Technology R\&D Project through the Korea Health Industry Development Institute (KHIDI), funded by the Ministry of Health \& Welfare, Republic of Korea (grant number: HI14C3477) and by a grant of Korea University Anam Hospital, Seoul, Republic of Korea (grant number: 01801031).

\section{AUTHOR CONTRIBUTIONS}

Conceptualization: H.J.C., B.K. Methodology: Jae M.L., C.D.K. Formal analysis: G.M. Funding acquisition: H.J.C, Y.T.J. Project administration: Jung M.L., S.H.K. Visualization: Y.S.S, S.H.U. Writing - original draft: Jung M.L. Writing - review and editing: E.S.K, H.S.C., B.K. Approval of final manuscript: all authors.

\section{ORCID}

Jung Min Lee

Geeho Min

Bora Keum https://orcid.org/0000-0003-3551-8638

https://orcid.org/0000-0001-9292-3520

https://orcid.org/0000-0003-0391-1945 
Jae Min Lee

Seung Han Kim

Hyuk Soon Choi

Eun Sun Kim

Yeon Seok Seo

Yoon Tae Jeen

Hoon Jai Chun

Hong Sik Lee

Soon Ho Um

Chang Duck Kim https://orcid.org/0000-0001-9553-5101

https://orcid.org/0000-0001-9247-9175

https://orcid.org/0000-0002-4343-6950

https://orcid.org/0000-0003-1820-459X

https://orcid.org/0000-0003-4171-6331

https://orcid.org/0000-0003-0220-3816

https://orcid.org/0000-0002-5539-361X

https://orcid.org/0000-0001-9726-5416

https://orcid.org/0000-0002-6390-2218

https://orcid.org/0000-0002-2829-6814

\section{REFERENCES}

1. Gentile M, De Rosa M, Cestaro G, Forestieri P. 2 L PEG plus ascorbic acid versus 4 L PEG plus simethicon for colonoscopy preparation: a randomized single-blind clinical trial. Surg Laparosc Endosc Percutan Tech 2013;23:276-280.

2. Kang SH, Hyun JJ. Preparation and patient evaluation for safe gastrointestinal endoscopy. Clin Endosc 2013;46:212-218.

3. Lee JM, Kim ES, Chun HJ, et al. Is there a change in patient preference for a female colonoscopist during the last decade in Korea? Clin Endosc 2018;51:72-79.

4. Abraham NS, Wieczorek P, Huang J, Mayrand S, Fallone CA, Barkun AN. Assessing clinical generalizability in sedation studies of upper GI endoscopy. Gastrointest Endosc 2004;60:28-33.

5. Heuss LT, Hanhart A, Dell-Kuster S, et al. Propofol sedation alone or in combination with pharyngeal lidocaine anesthesia for routine upper GI endoscopy: a randomized, double-blind, placebo-controlled, non-inferiority trial. Gastrointest Endosc 2011;74:1207-1214.

6. Standards of Practice Committee of the American Society for Gastrointestinal Endoscopy, Lichtenstein DR, Jagannath S, et al. Sedation and anesthesia in GI endoscopy. Gastrointest Endosc 2008;68:815-826.

7. Liu J, Liu R, Meng C, et al. Propofol decreases etomidate-related myoclonus in gastroscopy. Medicine (Baltimore) 2017;96:e7212.

8. Wang D, Wang S, Chen J, et al. Propofol combined with traditional sedative agents versus propofol- alone sedation for gastrointestinal endoscopy: a meta-analysis. Scand J Gastroenterol 2013;48:101-110.

9. Ye L, Xiao X, Zhu L. The comparison of etomidate and propofol anesthesia in patients undergoing gastrointestinal endoscopy: a systematic review and meta-analysis. Surg Laparosc Endosc Percutan Tech 2017;27:1-7.

10. Song JC, Lu ZJ, Jiao YF, et al. Etomidate anesthesia during ERCP caused more stable haemodynamic responses compared with propofol: a randomized clinical trial. Int J Med Sci 2015;12:559-565.

11. Shah SB, Chowdhury I, Bhargava AK, Sabbharwal B. Comparison of hemodynamic effects of intravenous etomidate versus propofol during induction and intubation using entropy guided hypnosis levels. J Anaesthesiol Clin Pharmacol 2015;31:180-185.

12. Kim MG, Park SW, Kim JH, et al. Etomidate versus propofol sedation for complex upper endoscopic procedures: a prospective

double-blinded randomized controlled trial. Gastrointest Endosc 2017;86:452-461.

13. Park CH, Park SW, Hyun B, et al. Efficacy and safety of etomidatebased sedation compared with propofol-based sedation during ERCP in low-risk patients: a double-blind, randomized, noninferiority trial. Gastrointest Endosc 2018;87:174-184.

14. Lee JM, Min G, Lee JM, et al. Efficacy and safety of etomidatemidazolam for screening colonoscopy in the elderly: a prospective double-blinded randomized controlled study. Medicine (Baltimore) 2018;97:e10635.

15. Qureshi WA, Zuckerman MJ, Adler DG, et al. ASGE guideline: modifications in endoscopic practice for the elderly. Gastrointest Endosc 2006;63:566-569.

16. Cohen LB, Delegge MH, Aisenberg J, et al. AGA Institute review of endoscopic sedation. Gastroenterology 2007;133:675-701.

17. Sachar H, Pichetshote N, Nandigam K, Vaidya K, Laine L. Continued midazolam versus diphenhydramine in difficult-to-sedate patients: a randomized double-blind trial. Gastrointest Endosc 2018;87:1297-1303.

18. Cotton PB, Eisen GM, Aabakken L, et al. A lexicon for endoscopic adverse events: report of an ASGE workshop. Gastrointest Endosc 2010;71:446-454.

19. Banno S, Kato M, Sunata Y, et al. Risk factor for vital signs fluctuation during colonoscopy under conscious sedation consisting of midazolam and meperidine. Dig Dis 2018;36:113-117.

20. Ead H. From Aldrete to PADSS: reviewing discharge criteria after ambulatory surgery. J Perianesth Nurs 2006;21:259-267.

21. Riphaus A, Geist C, Schrader K, Martchenko K, Wehrmann T. Intermittent manually controlled versus continuous infusion of propofol for deep sedation during interventional endoscopy: a prospective randomized trial. Scand J Gastroenterol 2012;47:1078-1085.

22. Upchurch CP, Grijalva CG, Russ S, et al. Comparison of etomidate and ketamine for induction during rapid sequence intubation of adult trauma patients. Ann Emerg Med 2017;69:24-33.

23. Eames WO, Rooke GA, Wu RS, Bishop MJ. Comparison of the effects of etomidate, propofol, and thiopental on respiratory resistance after tracheal intubation. Anesthesiology 1996;84:1307-1311.

24. Vargo JJ. Etomidate: coming to an endoscopy unit near you? Gastrointest Endosc 2017;86:462-463.

25. Ruth WJ, Burton JH, Bock AJ. Intravenous etomidate for procedural sedation in emergency department patients. Acad Emerg Med 2001;8:13-18.

26. Moon SH. Sedation regimens for gastrointestinal endoscopy. Clin Endosc 2014;47:135-140.

27. Triantafillidis JK, Merikas E, Nikolakis D, Papalois AE. Sedation in gastrointestinal endoscopy: current issues. World J Gastroenterol 2013;19:463-481.

28. Igea F, Casellas JA, González-Huix F, et al. Sedation for gastrointestinal endoscopy. Endoscopy 2014;46:720-731.

29. Toklu S, Iyilikci L, Gonen C, et al. Comparison of etomidate-remifentanil and propofol-remifentanil sedation in patients scheduled for colonoscopy. Eur J Anaesthesiol 2009;26:370-376. 
30. Hüter L, Schreiber T, Gugel M, Schwarzkopf K. Low-dose intravenous midazolam reduces etomidate-induced myoclonus: a prospective, randomized study in patients undergoing elective cardioversion. Anesth Analg 2007;105:1298-1302.

31. Zhou C, Zhu Y, Liu Z, Ruan L. Effect of pretreatment with midazolam on etomidate-induced myoclonus: a meta-analysis. J Int
Med Res 2017;45:399-406.

32. Meng QT, Cao C, Liu HM, et al. Safety and efficacy of etomidate and propofol anesthesia in elderly patients undergoing gastroscopy: a double-blind randomized clinical study. Exp Ther Med 2016;12:1515-1524. 